\title{
MicroRNAs in pancreatic cancer diagnosis and therapy
}

\author{
ROBERT SŁOTWIŃSKI ${ }^{1}$, GUSTAW LECH ${ }^{2}$, SYLWIA MAŁGORZATA SŁOTWIŃSKA ${ }^{3}$
}

${ }^{1}$ Department of Immunology, Biochemistry, and Nutrition, Medical University of Warsaw, Poland

${ }^{2}$ Department of General, Gastroenterological, and Oncological Surgery, Medical University of Warsaw, Poland

${ }^{3}$ Department of Conservative Dentistry, Medical University of Warsaw, Poland

\begin{abstract}
Pancreatic cancer remains a disease with very poor prognosis (only 5-6\% of patients are still alive after five years). Attempts to improve the results of treatment of pancreatic cancer focus on a better understanding of the pathogenesis, and non-invasive diagnostic methods (genetic testing from peripheral blood), which would create the possibility of early diagnosis and early surgical treatment before the onset of metastasis. New hopes for the improvement of early diagnosis and treatment of pancreatic ductal adenocarcinoma (PDAC) are associated with genetic testing of microRNA expression changes. A large body of evidence has revealed that microRNAs are aberrantly expressed in the serum and in cancer tissues and elicit oncogenic or tumour-suppressive functions. Selected microRNAs can distinguish pancreatic ductal adenocarcinoma from non-cancerous lesions of the pancreas. This review focuses on the involvement of microRNAs in the early diagnosis of pancreatic cancer. Research results related to the development of a novel therapeutic strategy based on the modulation of microRNA expressions for a better outcome in patients with pancreatic cancer are also presented.
\end{abstract}

Key words: pancreatic cancer, microRNA expression, diagnosis, anticancer therapy.

(Centr Eur J Immunol 2018; 43 (3): 314-324)

\section{Introduction}

Current diagnostic capabilities allow for early detection of pancreatic cancer and effective surgical treatment, but only in a small group of patients. Most patients are diagnosed in the period of significantly advanced disease, although it is known that the time required for pancreatic cancer cells to acquire the ability to form metastases can last up to several years, which should create favourable conditions for an early diagnosis. Unfortunately, small tumour lesions, especially in the inflamed tissues, are difficult to detect using routine imaging analysis. The combination of conventional tumour markers with mediators of the inflammatory response has increased their usefulness in monitoring and predicting the course of disease as well as possibilities to differentiate benign from malignant lesions $[1,2]$; however, from a clinical point of view, it has not been precisely determined to what extent these studies may affect the early diagnosis and survival in patients with pancreatic cancer. Still, a prevailing view (especially among clinicians) is that the ever-increasing number of biomarkers detected does not have a real impact on the early diagnosis of pancreatic cancer [3-5].

New hopes for the improvement of pancreatic cancer treatment are associated with genetic testing of microRNA
(miRNA) expression changes, the aim of which is to better understand the pathogenesis as well as diagnostic and therapeutic possibilities. Although more than 20 years has passed since the first detection of miRNA in Caenorhabditis elegans (lin-4), the interest of immunologists, biologists, and physicians of different specialties in this research field is increasing. This is connected with a better understanding of mechanisms of miRNA involvement in the pathogenesis of many diseases, and with potential diagnostic and therapeutic possibilities of using the results of these studies. MiRNA genes are located either in independent noncoding DNA loci or in the introns of protein-coding genes [6]. MicroRNA biogenesis includes three main steps: 1) in the nucleus miRNA genes are transcribed by RNA polymerase II to form pri-miRNAs, 2) the Drosha RNAase III endonuclease trims the pri-miRNAs to liberate a pre-miRNA hairpin, which is actively transported to cytoplasm by Ran-GTP and exportin-5, and 3) final maturation is processed in the cytoplasm, where Dicer RNase III endonuclease cleaves the pre-miRNA into a single-stranded mature miRNA, and then the mature miRNA binds to proteins of the Argonaute (Ago) family and assembles the RNA-induced silencing complex (RISC) [7-9]. Association of the miRNA-RISC with a target mRNA inhibits the translation of target mRNA or degrades the target

Correspondence: Prof. Robert Słotwiński, Department of Immunology, Biochemistry and Nutrition, Medical University of Warsaw,

3 W. Oczki St., 02-007 Warsaw, Poland, e-mail: robert_slotwinski@yahoo.com

Submitted: 3.12.2017; Accepted: 8.01.2018 


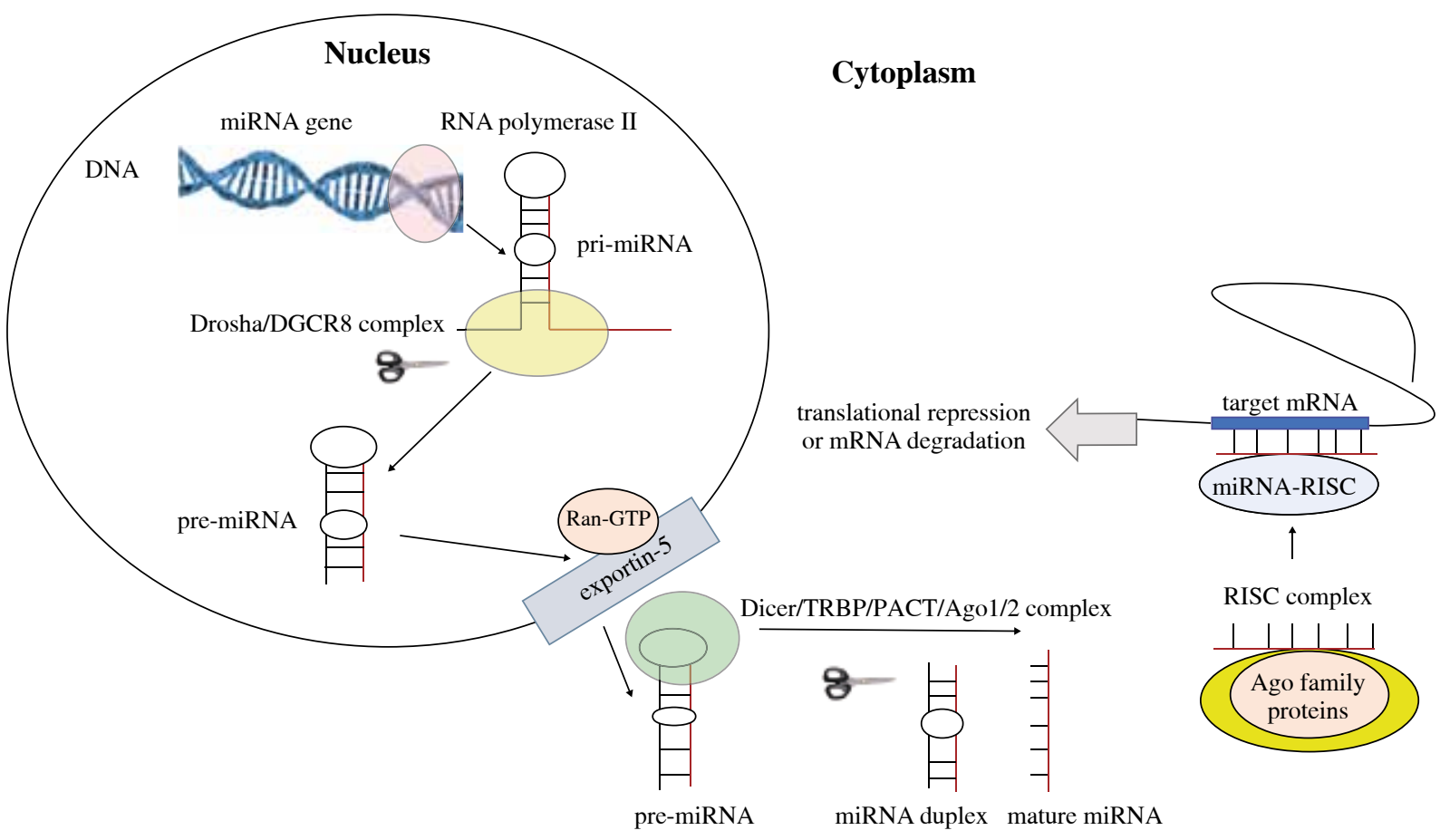

Fig. 1. Schematic mechanism of miRNA biogenesis and function

mRNA. The miRNA biogenesis pathway and function are summarised in Figure 1. According to the latest miRBase release (v21, June 2014, http://www.mirbase.org/), there are 28,645 entries representing hairpin precursor miRNAs from 223 species, expressing 35,828 mature miRNA products. It was found that miRNAs (19-25-nucleotide-long, non-coding RNAs) can control the expression of a single protein as well as whole groups of proteins relevant to important biological processes, either directly by affecting the regulators of pre-mRNA alternative splicing or indirectly by controlling the transcription factors. The expression of miRNAs can be regulated by epigenetic modulation, DNA copy number change, and genetic mutations. DNA methylation is crucially involved in the dysregulation of miRNAs in cancer [10]. For example, due to aberrant $\mathrm{CpG}$ methylation of its promoter, miR-34a is commonly silenced in pancreatic cancer but up-regulated in gastric cancer patients $[11,12]$. Hypermethylation of miR-34a gene has been found in $64 \%$ of pancreatic cancer tissues [13].

A large body of evidence revealed that 12 core signalling pathways (e.g. KRAS signalling, Hedgehog signalling, apoptosis, control of G1/S phase transition, and TGF- $\beta$ signalling) are genetically altered in approximately $80 \%$ of pancreatic cancer patients, and many miRNAs can regulate these signalling cascades and are aberrantly expressed $[14,15]$. The influence on transcription factors and signalling pathways associated with cell apoptosis is important in the regulation of innate and acquired immunity. The activation of oncogenes and disorders in apoptosis have become the primary factors in tumorigenesis [16]. Cancer cells become resistant to apoptosis, as a result of genetic disturbances and impaired expression of regulatory proteins [17]. The anti-apoptotic Bcl-2 family proteins are overexpressed on cancer cells. MiR-21 binding to Bcl-2 3'-UTR leads to overexpression of Bcl-2 and inhibits apoptosis in pancreatic cancer cells [18]. Conversely, miR-148a promotes apoptosis in pancreatic cancer by targeting Bcl-2 and acts as a tumour suppressor [19]. Moreover, miR491$5 \mathrm{p}$ and $\mathrm{miR}-15 \mathrm{a}-3 \mathrm{p}$ also promote pancreatic cells apoptosis by suppressing Bcl-XL gene expressions [20, 21], and miR-663 induces cell apoptosis and attenuates proliferation through Akt pathway activation [22]. MiRNAs play a major role in the regulation of cell growth, differentiation, programmed cell death, and lipid glucose metabolic pathways [23-26]. Active transport of these molecules or passive release into the peripheral blood is important in the process of intercellular communication and gene regulation [27-29]. Three mechanisms have been described for gene regulation via miRNA: translation repression, direct mRNA degradation, and miRNA-mediated mRNA decay. Interestingly, a recent study showed that a single miRNA may repress more than 100 mRNAs, and over $60 \%$ of human protein-coding genes are conserved targets of miRNAs [30].

The presence of circulating miRNA opens up the exciting possibility of analysing serum miRNAs as new noninvasive biomarkers for disease as well as for monitoring the response to interventions. MiRNAs are aber- 
rantly expressed in many tumours and elicit oncogenic or tumour-suppressive functions [19, 31-33]. Importantly for cancer diagnosis and better understanding of their pathogenesis, altered expression of miRNAs can be determined in serum, pancreatic fluid, stool, and tumour tissues, including paraffin sections [34]. Of particular interest is the involvement of miRNAs in the pathogenesis, early diagnostics, and treatment of pancreatic cancer [15, 34, 35]. This primarily results from the fact that pancreatic cancer remains a disease of unclear pathogenesis, and despite advances in diagnosis and treatment of cancer diseases, it is a disease with very poor prognosis (only 5-6\% of patients are alive after five years) [36, 37]. It occupies fourth place as a cause of death from cancer, and the mortality rate from pancreatic cancer is similar to the number of newly detected cases and continues to grow $[38,39]$. The current progress of knowledge has not yet resulted in a breakthrough in the early diagnostics and treatment of pancreatic cancer, which is inherently linked to the problem of late diagnosis, preventing radical surgery (at the time of diagnosis the tumour is unresectable in $80 \%$ of patients and there are already distant metastases) [40]. Only a small group of patients with resectable tumours have a five-year survival rate of $20 \%$ [41]. It should be emphasised that surgical treatment is still the most effective form of therapy. It is known that tumour resection of a diameter lower than $2 \mathrm{~cm}$ increases five-year survival to as much as $100 \%$ [42, 43]. Thus, the primary condition for improving the outcome of treatment is early diagnosis, which allows the detection (e.g. in peripheral blood) of changes in expression of miRNAs that promote pancreatic cancer progression.

\section{Tissue-derived microRNAs as biomarkers}

The study of Szafrańska et al. [44] has shown that miRNA (combination of miR-196a and miR-217 biomarkers) analysis of pancreatic fine-needle aspiration (FNA) biopsy samples can aid in the pathologic evaluation of suspicious cases and may provide a new strategy for improving the diagnosis of pancreatic diseases. The same author profiling of 377 microRNAs to investigate expression in normal pancreas, chronic pancreatitis, and pancreatic ductal adenocarcinoma (PDAC) tissues, as well as PDAC-derived cell lines, identified 26 miRNAs most prominently misregulated in PDAC [45]. Global microRNA expression profiling of microdissected tissues identifies miR-135b as a novel biomarker for pancreatic ductal adenocarcinoma [46]. Furthermore, studies of Lee et al. [47] showed that miRNA profiling of surgical pathology specimens (using formalin-fixed, paraffin-embedded specimens) differentiates serous cystadenoma from both premalignant pancreatic cystic neoplasms and PDAC and mucinous cystic neoplasm from branch duct-intraductal papillary mucinous neoplasm. An miRNA microarray from pancreatic cancer biopsy samples showed that 158 miRNAs were aberrantly expressed [48].
Of these aberrantly expressed miRNAs, expression of 51 miRNAs was increased and expression of 107 miRNAs was decreased. Further studies have shown that increase of miR21, miR-27a, miR-146a, miR-200a, and miR-196a expression levels and decrease of miR-217, miR-20a, and miR-96b expression levels occurs in pancreatic tumour tissue. The frequently downregulated miR-217 can regulate KRAS and function as a tumour suppressor in PDAC [49]. Therefore, miR-217 may serve as a useful therapeutic agent for miRNA-based PDAC therapy. Other tissue studies using miRNA microarray have shown increased expression of miR-21 with reduced levels of miR-34a and miR30d expression in patients with pancreatic cancer, which correlates with poor survival rates in patients with resectable pancreatic ductal adenocarcinoma. [50]. Studies of paraffin-embedded tissues from patients with pancreatic cancer differ from the study of fresh tissues, indicating the variable expression of other miRNAs [51]. In these studies, the expression of $664 \mathrm{mi}-$ croRNAs in tissue from 170 pancreatic adenocarcinomas and 107 ampullary adenocarcinomas was analysed, and the results were compared with chronic pancreatitis, normal pancreas, and duodenal adenocarcinoma. MiR-492, miR614, miR-198, and miR-196b were on the top of the list of differentially expressed microRNAs in both pancreatic and ampullary adenocarcinoma. In conclusion, the expression of a panel of 19 microRNAs could separate cancer tissue from non-neoplastic tissue very precisely. Hamada et al. $[52,53]$ identified miR-126 and miR-197 expression in PDAC, and these findings revealed that miR-126 acts as a tumour suppressor, while miR-197 induces epithelial-mesenchymal transition in pancreatic cancer cells by targeting p120 catenin. The authors of these studies have suggested that an miR-197/p120 catenin axis could be a novel therapeutic target. Other functional studies demonstrated that miR-367 promoted pancreatic cancer invasion in vitro and metastasis in vivo through downregulating Smad7 [54]. This suggests that miR-367 may be a promising therapeutic target for the treatment of human pancreatic cancer. Studies involving a large group of patients with pancreatic cancer have indicated decreased expressions of miR-31, miR122, miR-145, and miR-146a and increased expressions of miR-21, miR-155, miR-210, miR-221, and miR-222 in cancer tissues, but only miR-21 and miR-155 expression levels correlated with poor prognosis [55]. Among the examined miRNAs, special attention was paid to the lower expression of these miRNAs, which target the oncogenes (e.g. miR-16, miR-126, let-7d) and miRNA, whose increased expression (miR-21) appears in the malignant transformation from benign tumours [56]. MiR-21, as a well-known oncomiR, exerts an antiapoptotic effect by targeting the tumour suppressors (phosphatase and tensin homolog - PTEN and programmed cell death 4 - PDCD4) [57, 58].

The microRNAs profile may also be helpful in assessing the high risk of premalignant pancreatic lesions as intraductal papillary mucinous neoplasms (IPMN). Re- 
cent studies showed that expression of miR-100, miR-99a, miR-99b, miR-342-3p, miR-126, and miR-130a decreased with high-risk of IPMNs whereas expression of other microRNAs was elevated [59]. In addition, other studies have shown that certain miRNAs (e.g. miR-21, miR-155, miR-150, miR-148a, and miR-217) could differentiate benign IPMN from malignant IPMN (expression patterns of 846 human miRNAs were analysed) [60]. In IPMN with invasive pancreatic cancer, increased levels of miR-21 and miR-155, and decreased expressions of miR-148 and miR-217, were found. In other premalignant pancreatic lesions, including pancreatic intraepithelial neoplasia (PanIN) and mucinous cystic neoplasm (MCN), miRNA differential expression was also described. A recent review explored the current knowledge of miRNA sampling and reported that mainly miR-21, miR-155, and miR-196 were dysregulated in IPMN and PanIN lesions, suggesting their usefulness as early biomarkers of this disease [34]. The study investigated the expression profile of 735 human miRNAs in PanINs and PDAC and demonstrated that 65 miRNAs were differentially expressed in precursor lesions, of which 13 miRNAs were overexpressed [61]. In this study, the most highly expressed miRNA in PanIN-3 lesions (carcinoma in situ) was miR-196b. Moreover, miR196a and miR-196b showed high sensitivity and specificity for the diagnosis of PanIN lesions and familial pancreatic cancer [62]. According to other investigations, only miR-155 expression was significantly different in highgrade PanINs versus nontumoural tissues, and overexpression of miR-155 was detected in $80 \%$ of early pancreatic lesions [63]. MiR-21 has also been found to be overexpressed in PanIN and PDAC together with other miRNAs (e.g. miR-221, miR-222, miR-200, and miR-205) [64]. Other authors using four miRNAs (miR-10b-5p, miR202-3p, miR-210, and miR-375) could discriminate MCN from other pancreatic cystic neoplasms and PDAC with a sensitivity and specificity of $100 \%$ [47]. Logistic regression analysis revealed an endoscopic-ultrasound fine-needle aspiration (EUS-FNA) 2-miRNA classifier (miR-21 + miR-155) capable of distinguishing benign from malignant pancreatic lesions, with a sensitivity of $81.5 \%$ and a specificity of $85.7 \%$ (AUC 0.930) [65]. Thus, some miRNAs have been critical for the development and progression of pancreatic cancer, but differences in the results obtained by different authors limit their usefulness as early biomarkers of pancreatic cancer.

\section{Circulating microRNAs as biomarkers}

Discrimination between benign and malignant lesions on the basis of circulating miRNA in peripheral blood located in lipid or lipoprotein complexes (as apoptotic bodies, microvesicles, or exosomes) is another challenge for genetic non-invasive earliest diagnosis of pancreatic cancer. Importantly, in cancer diseases, there may be a cor- relation between the circulating miRNAs of tumour-derived exosomes and tumour miRNAs, which may influence the formation of distant cancer metastases, because miRNA is a signalling molecule used for communication between tumour cells and the environment in which they develop [66]. The combined analyses of four miRNAs (miR-21, miR-210, miR-155, and miR-196a) in plasma can discriminate patients with pancreatic cancer from normal healthy individuals with a sensitivity of $64 \%$ and a specificity of $89 \%$ [67]. The results of other studies have shown that expression levels of plasma miR-16, miR-21, miR-155, miR181a, miR-181b, miR-196a, and miR-210 were increased in pancreatic cancer patients compared to pancreatitis patients and normal adults [68]. Another study found that elevated serum miR-1290 expression distinguishes patients with low-stage pancreatic cancer from controls [69]. The latest study identified two diagnostic panels based on microRNA expression (38 miRNAs) in whole blood with the potential to distinguish patents with pancreatic cancer from healthy controls [70]. Interestingly, the combination of eight miRNAs has higher diagnostic sensitivity compared to CA19-9 and is also useful for identifying operative cancer cases [71]. The expression of miR-196a was up-regulated in patients with unresectable tumour of the pancreas and correlated with the cancer progression and poor prognosis [72]. Numerous studies have shown that elevated expression of selected microRNAs (plasma miR-221) correlates with distal metastases of pancreatic cancer or significantly decreases after tumour resection (plasma miR-221 and miR-18a) [73-75]. In other studies, it has been emphasised that an increased level of plasma miR-21 correlates with disease progression and poorer survival, and the plasma miR-483-3p level is useful for discriminating PDAC from IPMN [76]. Furthermore, increased serum expressions of miR-20a, miR-21, miR-24, miR-99a, miR-185, and miR-191 show high sensitivity and specificity in different stages of pancreatic cancer compared to controls and pancreatitis patients [77]. MiRNA expression profile in serum from 197 pancreatic cancer patients revealed miR-25 overexpression, and subsequent studies involving a larger group of patients have confirmed that serum miR-25 has strong potential as a novel biomarker for early detection of pancreatic cancer [78]. MiRNAs from serum-exosomes were also increased in pancreatic cancer patients [79]. The selected miR-1246, miR-4644, miR-3976, and miR-4306 were significantly upregulated in $83 \%$ of pancreatic cancer serum-exosomes, but rarely in control groups. Exosomes, small lipoprotein membranous vesicles secreted by all living cells, are a powerful diagnostic tool due to their relative stability and composition covering the whole range of cancer-related biomarkers, including miRNAs that are directly involved in gene expression control. The results of these studies were further evidence of the prognostic significance of peripheral blood miRNA assay. However, the clinical usefulness of these 
potential biomarkers has not been established in the monitoring of disease progression and efficacy of therapy. It can also be assumed that the usefulness of the most commonly used cancer markers (e.g. Ca19-9, CEA) is limited in the early diagnosis of pancreatic cancer, and the evaluation of new biomarkers (e.g. miRNAs) raises still more controversial opinions, thus requiring further studies [70, 80, 81]. Promising studies aimed at increasing the usefulness of CA 19-9 in the early diagnosis of pancreatic cancer are based on the parallel determination of the expression of miRNA panels $[68,82,83]$. The combination of miR-16, miR-196a plasma levels, and CA19-9 was more effective for pancreatic cancer diagnosis, especially in early tumour screening (85.2\% in Stage I) [68].

In summary, as shown by earlier studies, tumour-derived miRNA expression can be assayed using non-invasive, low-cost, precise, and rapid methods in peripheral blood (venous blood, plasma/serum), saliva, urine, peritoneal fluid, cerebral-spinal fluid, tears, breast milk, vaginal discharge, semen, and faeces [28, 29, 34, 84-87]. Studies published in recent years suggest that the expression of miRNAs may vary in different diseases, including neoplastic disorders (e.g. pancreatic cancer was shown to have an increased expression of miRNA-21, miR-210, miR-155, and miR-196a; colorectal cancer showed an increased expression of miRNA-29a, miR-17-3p, miR-221, miR-27b, miR-148, and miR-326; and gastric cancer had an increased expression of miRNA-221, miR-376c, miR744, miR-106b, and miR-20a in blood) and may exhibit tissue specificity that correlates with the expression of the same miRNAs in peripheral blood (e.g. in pancreatic cancer patients) $[29,34,35]$. It should also be noted that selected miRNAs (miR-18a, miR-21, miR-155, miR-185, miR-196a, miR-210, and miR-212) have been demonstrated (in pancreas tissue, serum, or plasma) by multiple groups to differentiate pancreatic ductal adenocarcinoma from non-cancerous lesions of the pancreas (Table 1) [45, 67, 88-92]. Furthermore, these miRNAs can regulate a wide variety of oncogenic biological processes by affecting the essential components of core signalling cascades

Table 1. MiRNA in pancreatic ductal adenocarcinoma

\begin{tabular}{|c|c|c|c|c|c|}
\hline Tissue-derived miRNAs & $\begin{array}{l}\text { Expression } \\
\text { profile }\end{array}$ & Reference & Circulating miRNAs & $\begin{array}{l}\text { Expression } \\
\text { profile }\end{array}$ & Reference \\
\hline $\begin{array}{l}\text { miR-21, miR-27a, miR-146a, miR-135b, } \\
\text { miR-196a, miR-200a }\end{array}$ & Up-regulated & {$[44,46,48,49]$} & $\begin{array}{l}\operatorname{miR}-21, \operatorname{miR}-155 \\
\text { miR-196a, miR-210 }\end{array}$ & Up-regulated & [67] \\
\hline miR-20a, and miR-96b, miR-217 & Down-regulated & & $\begin{array}{l}\text { miR-16, miR-21, } \\
\text { miR-155, miR181a, } \\
\text { miR-181b, miR-196a, } \\
\text { miR-210 }\end{array}$ & Up-regulated & {$[68]$} \\
\hline $\begin{array}{l}\text { miR-126, miR-141, miR-200c, miR-205, } \\
\text { miR-148, miR-216b, miR-217b }\end{array}$ & Down-regulated & {$[51,52]$} & $\begin{array}{l}\text { miR-26b, miR-34a, } \\
\text { miR-122, miR-126, } \\
\text { miR-145, miR-150, }\end{array}$ & Up-regulated & {$[70,72]$} \\
\hline $\operatorname{miR}-21$ & Up-regulated & & $\begin{array}{l}\text { miR-196a, miR-223, } \\
\text { miR-505, miR-636, } \\
\quad \text { miR-885.5p }\end{array}$ & & \\
\hline $\operatorname{miR}-197$ & Up-regulated & {$[53]$} & $\begin{array}{l}\text { miR-18a, miR-21, } \\
\text { miR-221, miR-483-3p }\end{array}$ & Up-regulated & {$[73-76]$} \\
\hline miR-31, miR-122, miR-145, miR0146a & Down-regulated & [55] & $\begin{array}{l}\operatorname{miR}-20 a, \operatorname{miR}-21 \\
\text { miR-24, miR-25, }\end{array}$ & Up-regulated & {$[77,78]$} \\
\hline miR-21, miR-155, miR-210, miR-221, miR-222 & Up-regulated & & $\begin{array}{l}\text { miR-99a, miR-185, } \\
\text { miR-191 }\end{array}$ & & \\
\hline $\begin{array}{l}\operatorname{miR}-100, \operatorname{miR}-99 a / b, \text { miR-126, miR-130a, } \\
\text { miR-342 }\end{array}$ & $\begin{array}{l}\text { Down-regulated } \\
\text { in IPMN }\end{array}$ & [59] & $\begin{array}{l}\operatorname{miR}-1246, \operatorname{miR}-4644 \\
\operatorname{miR}-3976, \operatorname{miR}-4306\end{array}$ & Up-regulated & {$[79]$} \\
\hline $\begin{array}{l}\text { miR-15b, miR-18a, miR-21, miR-29a/b/c, } \\
\text { miR-31, miR-95, miR-101, miR-103, miR-106b, } \\
\text { miR-146a, miR-155, miR-182, miR-190, } \\
\text { miR-193b, miR-194, miR-196b, miR-200a/b, } \\
\text { miR-203, miR-222, miR-338-3p, miR-429, } \\
\text { miR-486-3p, miR-93 }\end{array}$ & $\begin{array}{l}\text { Up-regulated } \\
\text { in PDAC and } \\
\text { PanIN }\end{array}$ & [61] & & & \\
\hline $\begin{array}{l}\text { miR-107, miR-139-3p/5p, miR-216a/b, miR-217, } \\
\text { miR-218,miR-483-5p }\end{array}$ & $\begin{array}{l}\text { Down-regulated } \\
\text { in PDAC and } \\
\text { PanIN }\end{array}$ & & & & \\
\hline miR-21, miR-155 & Up-regulated & [65] & & & \\
\hline
\end{tabular}

PDAC-pancreatic ductal adenocarcinoma; IPMN - intraductal papillary mucinous neoplasms; PanIN-pancreatic intraepithelial neoplasia 
(e.g. including apoptosis, control of cell cycle, or Hedgehog signalling) [15]. The results of experimental studies have, therefore, been used in attempts at early detection of PDAC and the development of new treatment in which miRNAs are therapeutic targets [93-95].

\section{MicroRNAs as therapeutic targets}

Particular attention should be paid to the inhibition of oncogenic miRNAs (e.g. miR-21, miR-155, miR-196a, miR-210, and miR-221) based on the use of antagomirs $[96,97]$. It has been successfully shown that antagomirs leads to long-lasting inhibition of specific miRNAs in mice [98]. Applying silencing strategies to selected miRNAs may alter the outcome of conventional therapeutics. Antisense oligonucleotides (ASOs) can inhibit up-regulated oncogenic miRNAs in tumours [99]. ASO hybridisation to the right mRNA may inhibit the process of replication, transcription, or translation. For instance, ASOs for miR-21 and miR-221 reduce proliferation of cancer cells, increase apoptosis by increasing the levels of their targets, and sensitise the effects of gemcitabine in pancreatic adenocarcinoma [100]. More recent research has indicated that antisense inhibition of miR-21 and miR-221 in tumour-initiating stem-like cells modulates tumorigenesis, metastasis, and chemotherapy resistance in pancreatic cancer [101]. The co-delivery of ASO-miR-21 and gemcitabine induces more cell apoptosis and inhibits the growth of pancreatic cancer cells to a greater extent than single ASO-miR-21 or gemcitabine treatment in vitro [102]. The downregulation of the oncogenic miR-21 by ASO results in upregulation of the tumour-suppressor genes PDCD4 and PTEN. Down-regulation of miR-221 by treatment of pancreatic cancer cells with isoflavone mixture or synthetic curcumin analogue $(\mathrm{CDF})$ inhibits proliferation of pancreatic cancer cells through up-regulation of PTEN, p2 $7^{\mathrm{kip} 1}$, p57 $7^{\mathrm{kip} 2}$, and PUMA, which are the tumour suppressors and targets of miR-221 [103]. In addition, curcumin analogue induced the expressions of miR-101, miR-146a, let-7, and the miR-200 family, inhibiting pancreatic tumour growth by switching on suppressor miRNAs [104]. A similar anti-tumour efficacy has been demonstrated with the administration of the miR-17-5p inhibitor [105]. MiR-17-5p inhibitor enhances chemosensitivity to gemcitabine via upregulation of the proapoptotic protein Bim expression in pancreatic cancer cells, which inhibits tumour cell proliferation, and increased apoptosis and caspase- 3 activity.

Another way to reduce the growth and invasive capacity of pancreatic cancer cells may be the enforced expression of miR-145 or miR-146a (e.g. by isoflavone), which targets oncogene (ITGA11, MAGEA4, SET RPA1, MCM2, ABCC1, SPTBN1, SPTLC1 or EGFR, IRAK-1, MTA-2) and are decreased in pancreatic cancer tissues $[106,107]$. As indicated by experimental studies, the putative tumour suppressor gene SELIL was downregulated by aberrantly upregulated has-mir-155 in human pancreatic ductal adenocarcinoma [108]. This study suggests that suppressing aberrantly upregulated microRNA may have an impact on PDAC growth. According to this concept, the reduction of miR-21 expression (miR-21 decreases the expression of SMAD7, a negative regulator of TGF- $\beta$ signalling) in pancreatic cancer cells and probably in tumour-associated fibroblasts, inhibits proliferation and increases apoptosis [109, 110]. Results of these studies revealed that increased levels of miR-21 in PDAC and PDAC-activated myofibroblasts are associated with poor prognosis. Overexpression of miR-21 in PDAC was also associated with chemo-resistance, and antagomir against miR-21 sensitised the cultured cells to 5-FU treatment [111]. Interestingly, the natural compound present in some fruits and cruciferous vegetables, such as broccoli and cabbage (Indole-3-carbinol/DIM), is also effective in enhancing sensitivity of pancreatic cancer cells to gemcitabine via downregulation of miR-21 and upregulation of miR-200, let-7 family, and miR-146a [112, 113]. Anti-cancer activity is also shown in resveratrol (present in grapes) by inhibiting miR-21 regulation of BcL-2 expression and inducing apoptosis of pancreatic cancer cells [114].

Other studies indicate that selected miRNA (miR-34b) inhibits pancreatic cancer metastasis through repression of oncogenic Smad3 [115]. It has also been found that the expression level of miR-34b is significantly decreased in pancreatic cancer. An interesting way of restoring the lost expression of selected miRNA is demethylation of miRNA-encoding genes. Re-expression of miR-34a by de-methylation reduces epithelial to mesenchymal transition (EMT) and the invasive capacity of pancreatic cancer cells [116]. Restoration of miR-34a expression increases apoptosis of pancreatic cancer cells by decreasing the expression level of anti-apoptotic proteins.

Other studies point to the nanotechnology that can be used in order to formulate potent anti-cancer agents to improve their physicochemical properties, such as poor aqueous solubility, or to prolong circulation times after administration resulting in improved efficacy. It has been demonstrated that the use of a nanoparticle-based delivery system for miRNAs that inhibit tumour growth (miR-34a, miR-150/miR-150-NF) can have potential implications in the treatment of pancreatic cancer [117, 118]. Experimental studies in which miRNAs were administered together with anti-cancer drugs are also promising, but further studies are needed. Immuno-histochemical analysis revealed decreased tumour cell proliferation with increased apoptosis in animals treated with a miR-205 and gemcitabine combination [119]. This study revealed that the combination formulation of miR-205 and gemcitabine reversed the gemcitabine resistance of pancreatic cancer cells. The co-delivery of small molecule Hedgehog inhibitor and miRNA for treating pancreatic cancer showed decreased tumour cell proliferation with increased apoptosis in animals treated with a miR-let $7 b$ 
and GDC-0449 combination [120]. A recent investigation of the molecular mechanisms underlying the metastasis of pancreatic cancer indicated that Bcellspecific Moloney murine leukaemia virus insertion site 1 (BMI1) was a direct target gene of miR452 in pancreatic cancer, and miR-452 expressions were downregulated in pancreatic cancer tissues, in metastatic tumours, and in pancreatic cancer cell lines [121]. In this study, overexpression of miR452 inhibited the migration and invasion of pancreatic cancer, at least partially, by knockdown of BMI1 expression. The results of these studies were not specific for pancreatic cancer; similar expression of miR-452 was found in non-small cell lung cancer [122], and changes in miR-452 expression have also been reported in other tumours; for example, miR-452 was demonstrated to be an oncogene in oesophageal cancer [123]. In another study miR-142-3p (from the Chinese herb Tripterygium wilfordii), a negative regulator of heat shock protein 70, was shown to reduce the proliferation of pancreatic cancer cells [124]. On the other hand, restoration of E-cadherin expression in pancreatic ductal adenocarcinoma (mouse model) treated with miR-101 inhibits tumour growth [125]. The results of these studies confirm the beneficial effect of modulation of the local inflammatory response in PDAC, although it is known that inflammatory response in individual patients differs and not all patients respond to the same therapy. Referring to miRNA-based therapy as indicated by the results of the above-mentioned studies, matching of effective and safe treatment would require evaluation of the expression profile of selected oncogenic and tumour suppressor miRNAs in each patient, which can easily be examined in peripheral blood before and during treatment.

\section{Conclusions, doubts, and perspectives}

Despite the growing body of evidence, assessment of the diagnostic value of miRNA aberrant expression in patients with pancreatic cancer requires further clinical trials.

The results of the presented studies have not yet led to a breakthrough in the early diagnosis of pancreatic cancer and still do not have a significant impact on outcome. There have been many optimistic results; nevertheless, many doubts have emerged that point to the need to revise previous research. The divergence in the results of studies presented by different authors impedes their interpretation. Most of the results of these studies are inconclusive, due to different research methodologies and other factors. It may be assumed that abnormal expression of microRNAs is a secondary phenomenon associated with pancreatic cancer progression, increasing malnutrition occurring in $80 \%$ of patients (including local nutrient limitation in the tumour environment), and metabolic changes (e.g. metabolic re-programming of cancer cells, anaerobic metabolism with loss of p53 function), and it has no direct connection with the process of tumourigenesis in the pancreas. For instance, it is well known that miR-155, which has an increased expression in pancreatic pre-cancerous (PanIN) and cancer cells, and plays a critical role in cancer progression, also participates in metabolic re-programming of tumour cells by increasing glucose consumption and lactate production. The process of metabolic re-programming is linked to the activation of oncogenes and/or suppression of tumour suppressor genes, but we still do not know exactly how mechanisms of metabolic re-programming modulate miRNA expression in patients with pancreatic cancer. Most studies indicate that interaction between metabolic transformation and abnormal expression of miRNAs creates a microenvironment that promotes tumour progression, increasing its invasiveness [126]. The most prominent metabolic alteration in cancer cells is increased glucose uptake and the use of glycolysis rather than mitochondrial respiration regardless of the presence of oxygen [127]. Interestingly, miR-195-5p, which has been found to be downregulated in bladder cancer, suppresses glucose uptake and proliferation of human bladder cancer T24 cells by regulating glucose transporter (GLUT3) expression [128]. Thus, regulating the expression of selected miRNAs can affect the metabolism of the tumour cells and reduce its invasiveness by limiting the delivery of appropriate nutrients (impaired glucose uptake mimics cancer cell starvation and stimulates apoptosis).

Another important problem of early diagnosis of pancreatic cancer is the occurrence of similar miRNA expression disorders in other cancers and inflammatory diseases. For example, the increased expression of miRNA-21 in the cited studies was present not only in pancreatic cancer, but also in other tumours (e.g. in lung, liver, or ovarian cancer, in glioblastoma, breast, and colon cancer) [29, 129]. On the other hand, it has been shown that dysregulation of miRNA-196a, miRNA-196b, miRNA-203, miRNA-210, miRNA-222, miRNA-217, and miR-375 was found only in PDAC tissues, whereas completely different miRNAs were abnormally expressed in both chronic pancreatitis and PDAC [45].

It is well acknowledged that microRNAs are present in peripheral blood both in physiological and pathological conditions; they have multidirectional and difficult to predict effects in individual patients (depending on the miRNA-mRNA compatibility, partial complementarity leads to a reduced protein expression by inhibition and/or suppression of translation, or mRNA degradation can occur, and regulatory pleiotropism may also be present), and the synthesis takes place not only in tumour cells, but probably also in all cells, including leukocytes, stem cells, or platelets [130-132]. Apoptosis of various cells (physiological/pathological), trauma, tissue necrosis associated with cancer (cancer-adjacent non-cancerous cell, stromal cells), tumour cell death, and lysis, all of which occur frequently, are probably other sources of variation in the expression of miRNAs [66, 133-135]; however, these mechanisms are still poorly understood. Furthermore, the extent of normal 
changes in miRNA expression in different populations has not been established. Hypothetically, altered expression of microRNAs may precede the appearance of clinical symptoms of pancreatic cancer even by a few years. Thus, another question arises - what processes are the main source of changes in the expression of miRNAs, and to what extent can they be specific to pancreatic cancer. A better understanding of the involvement of miRNAs in various pathological processes is essential for further development of a new research direction of non-invasive genetic diagnostics (genetic markers tested in peripheral blood) of pancreatic cancer and cancer stage (prognostic biomarkers) in patients requiring surgical treatment. Unfortunately, the current state of knowledge does not allow the use of miRNA-based therapy as a standard anticancer treatment. Clinical trials of miRNA-based therapies in cancer patients are ongoing, but, as indicated by experimental studies, this type of therapy could be an additional therapeutic strategy modulating the function of several genes and inhibiting pancreatic cancer growth.

\section{The authors declare no conflict of interest.}

\section{References}

1. Shaw VE, Lane B, Jenkinson C, et al. (2014): Serum cytokine biomarker panels for discriminating pancreatic cancer from benign pancreatic disease. Mol Cancer 13: 114.

2. Yako YY, Kruger D, Smith M, Brand M (2016): Cytokines as biomarkers of pancreatic ductal adenocarcinoma: A Systematic Review. PLoS One 11:e154016.

3. Słotwiński R, Słotwińska SM (2016): Diagnostic value of selected markers and apoptotic pathways for pancreatic cancer. Cent Eur J Immunol 41: 392-403.

4. Słotwiński R, Słotwińska SM (2016): Dysregulation of signaling pathways associated with innate antibacterial immunity in patients with pancreatic cancer. Cent Eur J Immunol 41: 404-418.

5. Kaur S, Baine MJ, Jain M, et al. (2012): Early diagnosis of pancreatic cancer: challenges and new developments. Biomark Med 6: 597-612.

6. Krol J, Loedige I, Filipowicz W (2010): The widespread regulation of microRNA biogenesis, function and decay. Nat Rev Genet 11: 597-610.

7. Bartel DP (2004): MicroRNAs: genomics, biogenesis, mechanism, and function. Cell 116: 281-297.

8. Cai X, Hagedorn CH, Cullen BR (2004): Human microRNAs are processed from capped, polyadenylated transcripts that can also function as mRNAs. RNA 10: 1957-1966.

9. Lee Y, Han AJ, et al. (2003): The nuclear RNase III Drosha initiates microRNA processing. Nature 425: 415-419.

10. Suzuki H, Maruyama R, Yamamoto E, Kai M (2012): DNA methylation and microRNA dysregulation in cancer. Mol Oncol 6: 567-578.

11. Chang TC, Wentzel EA, Kent OA, et al. (2007): Transactivation of miR-34a by p53 broadly influence gene expression and promotes apoptosis. Mol Cell 26: 745-752.
12. Liu R, Zhang C, Hu Z, et al. (2011): A five-microRNA signature identified from genome-wide serum microRNA expression profiling serves as a fingerprint for gastric cancer diagnosis. Eur J Cancer 47: 784-791.

13. Vogt M, Munding J, Grumer M, et al. (2001): Frequent concominant inactivation of miR-34a and miR-34b/c by $\mathrm{CpG}$ methylation in colorectal, pancreatic, mammary, ovarian, urothelial and renal cell carcinomas and soft tissue sarcomas. Virchows Arch 458: 313-322.

14. Jones S, Zhang X, Parsons DW, et al. (2008): Core signaling pathways in human pancreatic cancer revealed by global genomic analyses. Science 321: 1801-1806.

15. Sun L, Chua CYX, Tian W, et al. (2015): MicroRNA signaling pathway network in Pancreatic ductal adenocarcinoma. J Genet Genomics (JGG) 42: 563-577.

16. Hanahan D, Weinberg RA (2000): The hallmarks of cancer. Cell 100: 57-70.

17. Hanahan D, Weinberg RA (2011): Hallmarks of Cancer: The Next Generation. Cell 144: 646-674.

18. Dong J, Zhao YP, Zhou L, et al. (2011): Bcl-2 upregulation induced by miR-21 via a direct interaction is associated with apoptosis and chemoresistance in MIA PaCa-2 pancreatic cancer cells. Arch Med Res 42: 8-14.

19. Zhang R, Li M, Zang W, et al. (2014): MiR-148a regulates the growth and apoptosis in pancreatic cancer by targeting CCKBR and Bcl-2. Tumor Biol 35: 837-844.

20. Guo R, Wang Y, Shi WY, et al. (2012): MicroRNA miR-491$5 p$ targeting both TP53 and Bcl-XL induces cell apoptosis in SW1990 pancreatic cancer cells through mitochondria mediated pathway. Molecules 17: 14733-14747.

21. Druz A, Chen YC, Guha R, et al. (2013): Large-scale screening identifies a novel microRNA, miR-15a-3p, which induces apoptosis in human cancer cell lines. RNA Biol 10: 287-300.

22. Zang W, Wang Y, Wang T, et al. (2015): miR-663 attenuates tumor growth and invasiveness by targeting eEFIA2 in pancreatic cancer. Mol Cancer 14: 37.

23. Stark A, Brennecke J, Bushati N, et al. (2005): Animal microRNAs confer robustness to gene expression and have a significant impact on 3'UTR evolution. Cell 123: 1133-1146.

24. Cui Q, Yu Z, Purisima EO, Wang E (2006): Principles of microRNA regulation of a human cellular signaling network. Mol Syst Biol 2: 46.

25. Cui Q, Yu Z, Pan Y, et al. (2007): MicroRNAs preferentially target the genes with high transcriptional regulation complexity. Biochem Biophys Res Commun 352: 733-738.

26. Lynn FC (2009): Meta-regulation: microRNA regulation of glucose and lipid metabolism. Trends Endocrinol Metab 20: 452-459.

27. Mitchell PS, Parkin RK, Kroh EM, et al. (2008): Circulating microRNAs as stable blood-based markers for cancer detection. PNAS 105: 10513-10518.

28. Weber JA, Baxter DH, Zhang S, et al. (2010): The microRNA spectrum in 12 body fluids. Clin Chem 56: 1733-1741.

29. Lan H, Lu H, Wang X, Jin H (2015): MicroRNAs as Potential Biomarkers in Cancer: Opportunities and Challenges. Biomed Res Int 2015; 125094.

30. Friedman RC, Farh KK-H, Burge CB, Bartel DP (2009): Most mammalian mRNAs are conserved targets of microRNAs. Genome Res 19: 92-105.

31. Davidson-Moncada J, Papavasiliou FN, Tam W (2010): MicroRNAs of the immune system: roles in inflammation and cancer. Ann NY Acad Sci 1183: 183-194. 
32. O'Connell RM, Rao DS, Chaudhuri AA, Baltimore D (2010): Physiological and pathological roles for micro RNAs in the immune system. Nat Rev Immunol 10: 111-122.

33. Koturbash I, Zemp FJ, Pogribny I, Kovalchuk O (2011): Small molecules with big effects: the role of microRNAome in cancer and carcinogenesis. Mutat Res 722: 94-105.

34. Hernandez YG, Lucas AL (2016): MicroRNA in pancreatic ductal adenocarcinoma and its precursor lesions. World J Gastrointest Oncol 8: 18-29.

35. Subramani R, Gangwani L, Nandy SB, et al. (2015): Emerging roles of microRNAs in pancreatic cancer diagnosis, therapy and prognosis. Int J Oncol 47: 1203-1210.

36. Jemal A, Siegiel R, Xu J, Ward E (2010): Cancer statistics. CA Cancer J Clin 60: 277-300.

37. Bosetti C, Bertuccio P, Malvezzi M, et al. (2013): Cancer mortality in Europe, 2005-2009, and an overview of trends since 1980. Ann Oncol 24: 2657-2671.

38. Siegel RL, Miller KD, Jemal A (2015): Cancer statistics. CA Cancer J Clin 65: 5-29.

39. Raimondi S, Maisonneuve P, Lowenfels AB (2009): Epidemiology of pancreatic cancer: an overview. Nat Rev Gastroenterol Hepatol 6: 699-708.

40. Howlader N, Noone AM, Krapcho M, et al. (2013): SEER Cancer Statistics Review, 1975-2009 (Vintage 2009 Populations), National Cancer Institute. Bethesda. Accessed at http://seer.cancer. gov/csr/1975_2009_pops09 on 8 August 2013.

41. Winter JM, Cameron JL, Campbell KA, et al. (2006): 1423 pancreaticoduodenectomies for pancreatic cancer: a single institution experience. J Gastrointest Surg 10: 1199-1211.

42. Egawa S, Takeda K, Fukuyama S, et al. (2004): Clinicopathological Aspects of Small Pancreatic Cancer. Pancreas 28: 235-240.

43. Ariyama J, Suyama M, Ogawa K, Ikarai T (1986): Screening of pancreatic neoplasms and diagnostic rate of small pancreatic neoplasns. Nihon Rinsho 44: 1729-1734.

44. Szafrańska AE, Doleshal M, Edmunds HS, et al. (2008): Analysis of microRNAs in pancreatic fine-needle aspirates can classify benign and malignant tissues. Clin Chem 54: 1716-1724.

45. Szafrańska AE, Davison TS, John J, et al. (2007): MicroRNA expression alterations are linked to tumorigenesis and non-neoplastic processes in pancreatic ductal adenocarcinoma. Oncogene 26: $4442-4452$.

46. Munding JB, Adai AT, Maghnouj A, et al. (2012): Global microRNA expression profiling of microdissected tissues identifies miR-135b as a novel biomarker for pancreatic ductal adenocarcinoma. Int J Cancer 131: E86-E95.

47. Lee LS, Szafrańska-Schwarzbach AE, Wylie D, et al. (2014): Investigating MicroRNA expression profiles in pancreatic cystic neoplasms. Clin Transl Gastroenterol 5: e47.

48. Hong TH, Park IY (2014): MicroRNA expression profiling of diagnostic needle aspirates from surgical pancreatic cancer specimens. Ann Surg Treat Res 87: 290-297.

49. Zhao W-G, Yu S-A, Lu Z-H, et al. (2010): The miR-217 microRNA functions as a potential tumor suppressor in pancreatic ductal adenocarcinoma by targeting KRAS. Carcinogenesis 31 : 1726-1733.

50. Jamieson NB, Morran DC, Morton JP, et al. (2012): MicoRNA molecular profiles associated with diagnosis, clinicopathologic criteria, and overall survival in patients with resectable pancreatic ductal adenocarcinoma. Clin Cancer Res 18: 534-545.

51. Schultz NA, Werner J, Willenbrock H, el al. (2012): MicroRNA expression profiles associated with pancreatic adenocarcinoma and ampullary adenocarcinoma. Mod Pathol 25: 1609-1622.
52. Hamada S, Satoh K, Fujibuchi W, et al. (2012): MiR-126 acts as a tumor suppressor in pancreatic cancer cells via the regulation of ADAM9. Mol Cancer Res 10: 3-10.

53. Hamada S, Satoh K, Miura S, et al. (2013): MiR-197 induces epithelial-mesenchymal transition in pancreatic cancer cells by targeting p120 catenin. J Cel Physiol 228: 1255-1263.

54. Zhu Z, Xu Y, Zhao J, et al. (2015): miR-367 promotes epithelial-to-mesenchymal transition and invasion of pancreatic ductal adenocarcinoma cells by targeting the Smad7-TGF-b signalling pathway. Brit J Cancer 112: 1367-1375.

55. Papaconstantinou IG, Manta A, Gazouli M, et al. (2013): Expression of microRNAs in patients with pancreatic cancer and its prognostic significance. Pancreas 42: 67-71.

56. Jiao LR, Frampton AE, Jacob J, et al. (2012): MicroRNAs targeting oncogenes are down-regulated in pancreatic malignant transformation from benign tumors. PLoS One 7: e32068.

57. Meng F, Henson R, Wehbe-Janek H, et al. (2007): MicroRNA-21 regulates expression of the PTEN tumor suppressor gene in human hepatocellular cancer. Gastroenterology 133: 647-658.

58. Frankel LB, Christoffersen NR, Jacobsen A, et al. (2008): Programmed cell death 4 (PDCD4) is an important functional target of the microRNA miR-21 in breast cancer cells. J Biol Chem 283: 1026-1033.

59. Permuth-Wey J, Chen YA, Fisher K, et al. (2015): A genome-wide investigation of microRNA expression identifies biologically-meaningful microRNAs that distinguish between high-risk an low-risk intraductal papillary mucinous neoplasms of pancreas. PLoS One 10: e0116869.

60. Lubezky N, Loewenstein S, Ben-Haim M, et al. (2013): MicroRNA expression signatures in intraductal papillary mucinous neoplasm of pancreas. Surgery 153: 663-672.

61. Yu J, Li A, Hong SM, et al. (2012): MicroRNA alterations of pancreatic intraepithelial neoplasias. Clin Cancer Res 18: 981-992.

62. Slater EP, Strauch K, Rospleszcz S, et al. (2014): MicroRNA-196a and -196b as potential biomarkers for the early detection of familial pancreatic cancer. Transl Oncol 7: 464-471.

63. Ryu JK, Hong SM, Karikari CA, et al. (2010): Aberrant MicroRNA-155 expression is an early event in the multistep progression of pancreatic adenocarcinoma. Pancreatology 10: 66-73.

64. du Rieu MC, Torrisani J, Selves J, et al. (2010): MicroRNA-21 is induced early in pancreatic ductal adenocarcinoma precursor lesions. Clin Chem 56: 603-612.

65. Frampton AE, Krell J, Prado MM, et al. (2016): Prospective validation of microRNA signatures for detecting pancreatic malignant transformation in endoscopic-ultrasound guided fine-needle aspiration biopsies. Oncotarget 7: 28556-28569.

66. Kasaka N, Iguchi H, Ochiya T (2010): Circulating microRNA in body fluid: a new potential biomarker for cancer diagnosis and prognosis. Cancer Sci 101: 2087-2092.

67. Wang J, Chen J, Chang P, et al. (2009): MicroRNAs in plasma of pancreatic ductal adenocarcinoma patients as novel blood-based biomarkers of disease. Cancer Prev Res (Phila Pa) 2: 807-813.

68. Liu J, Gao Y, Li Z, et al. (2012): Combination of plasma microRNAs with serum CA19-9 for early detection of pancreatic cancer. Int J Cancer 131: 683-691.

69. Li A, Yu J, Kim H, et al. (2013): MicroRNA array analysis finds elevated serum miR-1290 accurately distinguishes patients with low-stage pancreatic cancer from healthy and disease controls. Clin Cancer Res 19: 3600-3610.

70. Schultz NA, Dehlendorff C, Jensen BV, et al. (2014): MicroRNA Biomarkers in Whole Blood for Detection of Pancreatic Cancer. JAMA 311: 392-404. 
71. Kojima M, Sudo H, Kawauchi J, et al. (2015): MicoRNA markers for diagnosis of pancreatic and biliary-tract cancers. PLoS One 10: e0118220.

72. Kong X, Du Y, Wang G, et al. (2011): Detection of differentially expressed microRNAs in serum of pancreatic ductal adenocarcinoma patients: miR-196a could be potential marker for poor prognosis Dig Dis Sci 56: 602-609.

73. Morimura R, Komatsu S, Ichikawa D, et al. (2011): Novel diagnostic value of circulating miR-18a in plasma of patients with pancreatic cancer. Br J Cancer 105: 1733-1740.

74. Kawaguchi T, Komatsu S, Ichikawa D, et al. (2013): Clinical impact of circulating miR-221 in plasma of patients with pancreatic cancer. Br J Cancer 108: 361-369.

75. Komatsu S, Ichikawa D, Takeshita H, et al. (2014): Circulating miR-18a: a sensitive cancer screening biomarker in human cancer. In Vivo 28: 293- 297.

76. Abue M, Yikoyama M, Shibuya R, et al. (2015): Circulating miR-483-3p and miR-21 is highly expressed in plasma of pancreatic cancer Int J Oncol 46: 539-547.

77. Liu R, Chen X, Du Y, et al. (2012): Serum microRNA expression profile as a biomarker in the diagnosis and prognosis of pancreatic cancer. Clin Chem 58: 610-618.

78. Deng T, Yuan Y, Zhang Chu, et al. (2016): Identification of circulating miR-25 as a potential biomarker for pancreatic cancer diagnosis. Cell Physiol Biochem 39: 1716-1722.

79. Madhavan B, Yue S, Galli U, et al. (2015): Combined evaluation of a panel of protein and miRNA serum-exosome biomarkers for pancreatic cancer diagnosis increases sensitivity and specificity. Int J Cancer 136: 2616-2627.

80. Costello E, Greenhalf W, Neoptolemos JP (2012): New biomarkers and targets in pancreatic cancer and their application to treatment. Nat Rev Gastroenterol Hepatol 9: 435-444.

81. Kishikawa T, Otsuka M, Ohno M, et al. (2015): Circulating RNAs as new biomarkers for detecting pancreatic cancer. World J Gastroenterol (WJG) 21: 8527-8540.

82. Li Y, Sarkar FH (2016): MicroRNA targeted therapeutic approach for pancreatic cancer 12: 326-337.

83. Buchsbaum DJ, Croce CM (2014): Will detection of microRNA biomarkers in blood improve the diagnosis and survival of patients with pancreatic cancer? JAMA 311: 363-365.

84. Cortez MA, Bueso-Ramos C, Ferdin J, et al. (2011): MicroRNAs in body fluids--the mix of hormones and biomarkers. Nat Rev Clin Oncol 8: 467-477.

85. Link A, Becker V, Goel A, et al. (2012): Feasibility of fecal microRNAs as novel biomarkers for pancreatic cancer. PLoS One 7:e42933.

86. Kosaka N, Izumi H, Sekine K, Ochiya T (2010): microRNA as a new immune-regulatory agent in breast milk. Silence 1: 7.

87. Li H, Huang S, Guo C, et al. (2012): Cell-Free Seminal mRNA and MicroRNA Exist in Different Forms. PLoS One 7: e34566.

88. Tang S, Bonaroti J, Unlu S, et al. (2013): Sweating the small stuff: microRNAs and genetic changes define pancreatic cancer. Pancreas 42: 740-759.

89. Liu M, Du Y, Gao J, et al. (2013): Aberrant expression miR196 is associated with abnormal apoptosis, invasion, and proliferation of pancreatic cancer cells. Pancreas 42: 1169-1181.

90. Habbe N, Koostra JB, Mendell JT, et al. (2009): MicroRNA-155 is a biomarker of early pancreatic neoplasia. Cancer Biol Ther 8: 340-346.

91. Bloomston M, Frankel WL, Petrocca F, et al. (2007): MicroRNA expression patterns to differentiate pancreatic adenocarcinoma from normal pancreas and chronic pancreatitis. JAMA 297: 1901-1908.
92. Caponi S, Funel N, Frampton AE, et al. (2013): The good, the bad and ugly: a tale of miR-101, miR-21 and miR-155 in pancreatic intraductal papillary mucinous neoplasms. Ann Oncol 24: 734-741.

93. Papaconstantinou IG, Lykoudis PM, Gazouli M, et al. (2012): A review on the role of microRNA in biology, diagnosis, and treatment of pancreatic adenocarcinoma. Pancreas 41: 671677.

94. Keklikoglou I, Hosaka K, Bender C, et al. (2015). MicroRNA-206 functions as a pleiotropic modulator of cell proliferation, invasion and lymphangiogenesis in pancreatic adenocarcinoma by targeting ANXA2 and KRAS genes. Oncogene 34: 4867-4878.

95. Sun T, Kong X, Du Y, Li Z (2014): Aberrant MicroRNAs in pancreatic cancer: Researches and clinical implications. Gastroenterol Res Pract 2014: 386561.

96. Song S, Ajani JA (2013): The role of microRNAs in cancers of upper gastrointestinal tract. Nat Rev Gastroenterol Hepatol 10: $109-118$.

97. Pramanik D, Campbell NR, Karikari C, et al. (2011): Restitution of tumor suppressor microRNAs using a systemic nanovector inhibits pancreatic cancer growth in mice. Mol Cancer Ther 10: 1470-1480.

98. Krutzfeldt J, Rajewsky N, Braich R, et al. (2005): Silencing of microRNAs in vivo with 'antagomirs'. Nature 438: 685-689.

99. Esau CC (2008): Inhibition of microRNA with antisense oligonucleotides. Methods 44: 55-60.

100. Park JK, Lee EJ, Esau C, Schmittgen TD (2009): Antisense inhibition of microRNA-21 or -221 arrests cell cycle, induces apoptosis, and sensitizes the effects of gemcitabine in pancreatic adenocarcinoma. Pancreas 38: e190-e199.

101. Zhao Y, Zhao L, Ischenko I, et al. (2015): Antisense inhibition of microRNA-21 and miroRNA-221 in tumor-initiating stem-like cells modulates tumorigenesis, metastasis, and chemotherapy resistance in pancreatic cancer. Targ Oncol 10: 535-548.

102. Li Y, Chen Y, Li J, et al. (2017): Co-delivery of microRNA-21 antisense oligonucleotides and gemcitabine using nanomedicine for pancreatic cancer therapy. Cancer Sci 108: 1493-1503.

103. Sarkar S, Dubaybo H, Ali S, et al. (2013): Down-regulation of miR-221 inhibits proliferation of pancreatic cancer cells through up-regulation of PTEN, p2 $7^{\text {kip1 }}, \mathrm{p} 57^{\text {kip2 }}$, and PUMA. Am J Cancer Res 3: 465-477.

104. Bao B, Ali S, Banerjee S, et al. (2012): Curcumin analogue CDF inhibits pancreatic tumor growth by switching on suppressor microRNAs and attenuating EZH2 expression. Cancer Res 72: 335-345.

105. Yan HJ, Liu WS, Sun WH, et al. (2012): miR-17-5p inhibitor enhances chemosensitivity to gemcitabine via upregulating Bim expression in pancreatic cancer cells. Dig Dis Sci 57: 3160-3167.

106. Huang TC, Renuse S, Pinto S, et al. (2015): Identification of miR-145 targets through an integrated omics analysis. Mol Biosyst 11: 197-207.

107. Li Y, VandenBoom TG, Wang Z, et al. (2010): miR-146a suppresses invasion of pancreatic cancer cells. Cancer Res 70: 1486-1495.

108. Pramanik D, Camphel NR, Karikari C, et al. (2013): Putative tumor suppressor gene SELIL was downregulated by aberrantly upregulated has-mir-155 in human pancreatic ductal adenocarcinoma. Mol Carcinog 53: 711-712. 
109. Bhatti I, Lee A, James V, et al. (2011): Knockdown of microRNA-21 inhibits proliferation and increases cell death by targeting programed cell 4 (PDCD4) in pancreatic ductal adenocarcinoma. J Gastrointest Surg 15: 199-208.

110. Kadera BE, Li L, Toste PA, et al. (2013): MicroRNA-21 in pancreatic ductal adenocarcinoma tumor-associated fibroblasts promotes metastasis. PLoS One 8: e71978.

111. Hwang JH, Voortman J, Giovannetti E, et al. (2010): Identification of microRNA-21 as a biomarker for chemoresistance and clinical outcome following adjuvant therapy in resectable pancreatic cancer. PloS One 5: e10630.

112. Paik WH, Kim HR, Park JK, et al. (2013): Chemosensitivity Induced by Down-regulation of MicroRNA-21 in Gemcitabine-resistant Pancreatic Cancer Cells by Indole-3-Carbinol. Anticancer Res 33: 1473-1482.

113. Li Y, VandenBoom TG, Kong D, et al. (2009): Up- regulation of miR-200 and let-7 by natural agents leads to the reversal of epithelial-to-mesenchymal transition in gemcitabine-resistant pancreatic cancer cells. Cancer Res 69: 67046712.

114. Liu P, Liang H, Xia Q, et al. (2013): Resveratrol induces apoptosis of pancreatic cancer cells by inhibiting miR-21 regulation of BCL-2 expression. Clin Transl Oncol 15: 741746.

115. Liu C, Cheng H, Shi S, et al. (2013): MicroRNA-34b inhibits pancreatic cancer metastasis through repressing Smad3. Curr Mol Med 13: 467-478.

116. Nalls D, Tang SN, Rodova M, et al. (2011): Targeting epigenetic regulation of miR-34a for treatment of pancreatic cancer by inhibition of pancreatic cancer stem cells. PLoS One 6: e24099.

117. Arora S, Swaminathan SK, Kirtane A, et al. (2014): Synthesis characterization and evaluation of poly(D,L-lactide-coglycolide)-based nanoformulation of miRNA-150 potential implications for pancreatic cancer therapy. Int J Nanomedicine 9: 2933-2942.

118. Hu QL, Jiang QY, Jin X, et al. (2013): Cationic microRNA-delivering nanovectors with bifunctional peptides for efficient treatment of PANC-1 xenograft model. Biomaterials 34: 2265-2276.

119. Mittal A, Chitkara D, Behrman SW, Mahato RI (2014): Efficacy of gemcitabine conjugated and miRNA-205 complexed micelles for treatment of advanced pancreatic cancer. Biomaterials 35: 7077-7087.

120. Kumar V, Mondal G, Slavik P, et al. (2015): Codelivery of Small Molecule Hedgehog Inhibitor and miRNA for Treating Pancreatic Cancer. Mol Pharm 12: 1289-1298.

121. Li H, Wu Y, Li P (2017): MicroRNA452 suppresses pancreatic cancer migration and invasion by directly targeting Bcellspecific Moloney murine leukemia virus insertion site 1. Oncol Lett 14: 3235-3242.

122. He Z, Xia Y, Pan C, et al. (2015): Upregulation of miR452 inhibits metastasis of nonsmall cell lung cancer by regulating BMI1. Cell Physiol Biochem 37: 387398.

123. Liu SG, Qin XG, Zhao BS, et al. (2013): Differential expression of miRNAs in esophageal cancer tissue. Oncol Lett 5: 16391642.

124. MacKenzie TN, Mujumdar N, Banerjee S, et al. (2013): Triptolide induces the expression of miR-142-3p: A negative regulator of heat shock protein 70 and pancreatic cancer cell proliferation. Mol Cancer Ther 12: 1266-1275.
125. Qazi AMI, Gruzdyn O, Semaan A, et al. (2012): Restoriation of E-catherin expression in pancreatic ductal adenocarcinoma treated with microRNA-101. Surgery 152: 704-713.

126. Tomasetti M, Amati M, Santarelli L, Neuzil J (2016): MicroRNA in metabolic re-programming and their role in tumorigenesis. Int J Mol Sci 17: 754-773.

127. Hanahan D, Weinberg RA (2011): Hallmarks of cancer: The next generation. Cell 144: 646-674.

128. Fei X, Qi M, Wu B, et al. (2012): MicroRNA-195-5p suppresses glucose uptake and proliferation of human bladder cancer T24 cells by regulating GLUT3 expression. FEBS Lett 586: 392-397.

129. Ji W, Sun B, Su Ch (2017): Targeting MicroRNAs in Cancer Gene Therapy. Genes (Basel) 8: 21.

130. Baj-Krzyworzeka M, Szatanek R, Węglarczyk K, et al. (2007): Tumor-derived microvesicles modulate biological activity of human monocytes. Immunol Lett 113: 76-82.

131. Belting M, Wittrup A (2008): Nanotubules, exosomes, and nucleic acid-binding peptides provide novel mechanisms of intercellular communication in eukaryotic cells: implications in health and disease. J Cell Biol 183: 1187-1191.

132. Ratajczak J, Miekus K, Kucia M, et al. (2006): Embryonic stem cell-derived microvesicles reprogram hematopoietic progenitors: evidence for horizontal transfer of mRNA and protein delivery. Leukemia 20: 847-856.

133. Laterza OF, Lim L, Garrett-Engele PW, et al. (2009): Plasma MicroRNAs as diagnostically sensitive and specific biomarkers of tissue injury. Clin Chem 55: 1977-1983.

134. Liu J, van Mil A, Vrijsen K, et al. (2011): MicroRNA-155 prevents necrotic cell death in human cardiomyocyte progenitor cells via targeting RIP1. J Cell Mol Med 15: 1474-1482.

135. Ross SA, Davis CD (2011): MicroRNA, Nutrition, and cancer prevention. Adv Nutr 2: 472-485. 